\title{
DIFERENÇAS INTERGERACIONAIS NO CONTEXTO BRASILEIRO: reflexões e perspectivas
}

\author{
Patrick Alexander Wachholz* \\ Fabrizio Kieser Fiamoncini ${ }^{* *}$
}

\section{Resumo}

A exposição de um grupo de pessoas com idades similares a problemas históricos e experiências sociais, políticas e culturais semelhantes é o que define o conceito de geração. Através da análise dos eventos políticos e sócio-culturais a que foram submetidos os jovens de diferentes gerações nas últimas décadas, criou-se uma classificação para os padrões norteamericanos, que ora adicionamos ao contexto histórico brasileiro, de modo a estimular o debate sobre as percepções dessas diferenças na gênese de muitos dos atuais conflitos entre velhos e jovens.

Palavras-chave: Relação entre Gerações. Efeito de Coortes. Intergeracionalidade.

\section{Introdução}

Apesar das questões etárias terem sido uma presença constante no desenvolvimento da história da humanidade, foi somente nos últimos 50 anos, com a evidência do envelhecimento populacional como um fenômeno universal (KALACHE; VERAS; RAMOS, 1987), que a importância das diferenças intergeracionais na experiência coletiva do envelhecer parece, conforme assinala Coelho (1988), ter chamado a atenção de cientistas sociais e gerontológos.

O conceito de geração, conforme assinalam Laufer e Bengston (1974), é fundamentalmente definido como um fenômeno de pessoas com idades similares que vivenciam ou vivenciaram problemas históricos e concretos, além de experiências comuns com os sistemas político, social, econômico e cultural.

\footnotetext{
* Médico, especialista em Geriatria pela Sociedade Brasileira de Geriatria e Gerontologia, pósgraduado em Gerontologia pela Universidade Federal de Santa Catarina. E-mail: p_wachholz@hotmail.com

${ }^{* *}$ Fisioterapeuta, pós-graduado em Gerontologia pela Universidade Federal de Santa Catarina.
} 
Acreditamos que o cerne das relações de vínculo e poder entre os indivíduos de gerações diferentes tenham sido rascunhados na mesma época em que o homem pré-histórico foi capaz de manter-se vivo por mais de duas décadas, sendo capaz de observar e interagir com sua própria prole.

Segundo Rifiotis (1995), a idade sempre foi tida como uma dimensão social que, historicamente, proporcionava maior status a um indivíduo, tanto por razões quantitativas (havia menos idosos) como qualitativas (a opinião do idoso era ouvida e valorizada com mais ênfase do que a inovação).

A perda de papéis sociais, indubitavelmente, é considerada hoje como um dos processos mais característicos do envelhecimento (SEIFFERT, 2001). Em função destas perdas consecutivas e do abandono muitas vezes traumático destes papéis, Moragas (1997) acredita que o idoso de hoje foi obrigado a assumir um papel sem papel, fenômeno creditado por outros autores com o título de degerontização (MORIN, 1967).

Conforme assinala Rifiotis (1995), o processo de socialização é fundamental para a continuidade social e, como sabemos, está diretamente dependente da divisão dos grupos etários e dos ritos de iniciação e relações estabelecidos entre pais e filhos, através dos quais os segundos passam a ser institucionalizados para a vida em comunidade pelos primeiros.

As relações entre os membros de um mesmo grupo ou classe de idades (geração) tendem a ser baseadas em preceitos de igualdade e solidariedade (ditos horizontais), enquanto as relações familiares (de linhagem) tendem a ser predominantemente baseadas na autoridade e na hierarquia (MORAGAS, 1997).

Com o objetivo de facilitar a assimilação da importância do status e papel social da família, Moragas (1997) propõe que esta seja dividida em família de orientação e família de procriação, sendo a primeira a família em que se nasce, e a segunda a família formada a partir do enlace com terceiros, tendo por finalidade a procriação.

Ao estabelecermos esta dupla natureza de família observamos que existe uma complexa rede envolvida na interação dos diferentes papéis sociais que são construídos e negociados entre os indivíduos envolvidos. Relações incluídas nestas dinâmicas familiares podem ser tanto baseadas em fortes laços de solidariedade quanto baseadas nas rígidas relações hierárquicas de linhagem.

Acreditamos que as relações intergeracionais (entre as diferentes gerações de grupos familiares ou sociais) provavelmente são assimétricas 
devido ao forte impacto que a percepção dos diferentes papéis sociais exerce na relação de poder entre estes indivíduos.

Durante centenas de anos, segundo Morin (1967), as gerações mais velhas criaram sua descendência obedecendo aos princípios de educação que haviam sido transmitidos pelos seus pais (recebidos, por sua vez, de seus próprios pais, e assim por diante), introduzindo apenas poucas mudanças, que passavam a ser exigidas pelas características dos novos tempos. O mesmo autor assinala que "[ ... ] o desenvolvimento [ ... ] parece ter contribuído para a progressiva degradação da autoridade dos velhos." (MORIN, 1967 p. 61).

São exatamente as características assimétricas observadas nestas relações de disputa pelo poder e por papéis sociais entre grupos de diferentes gerações que, segundo Rifiotis (1995), culminaram com as primeiras citações do termo conflito de gerações.

As diferenças nos comportamentos transmitidos pelas linhagens hierárquicas prévias e os comportamentos assimilados pelos membros mais jovens através de influências externas (meios de comunicação, comportamentos culturais, etc.) originam o drama da sucessão: as velhas gerações reagem às inovações e propostas das gerações mais novas a fim de preservar sua continuidade e extensão pessoal no futuro.

As gerações mais novas, por sua vez, desenvolvem valores opostos, e segundo Moragas (1997), chegam ao clímax com as mudanças na configuração cultural vigente.

Ou seja, os primeiros preocupam-se em transmitir com sucesso seus valores, a fim de justificar sua própria existência, enquanto as gerações mais novas buscam estabilizar seus próprios valores, recorrendo a estratégias compatíveis com as atuais modernidades para isto.

Goldani (1999, p. 229) sugere que exista um contrato intergeracional entre os membros de uma família, mantido por um conjunto de fatores que incluem desde laços de afeto e sentimentos de reciprocidade, até incentivos econômicos ou sanções negativas. Afirma ainda que: "[ ... ] os sentimentos de obrigação que atravessam as gerações são influenciados não só pelas experiências únicas dos indivíduos de uma família particular, mas, também, por circunstâncias históricas específicas."

Diversos modelos são atualmente sugeridos para a análise das diferenças intergeracionais: os modelos econômicos utilizados por Turra e Queiroz (2005), os modelos de grupos intergeracionais defendidos por Silveira 
(2002), os ciclos vitais da família (CASTILHO, [2003?]), ou os modelos sócio-políticos citados por Goldani (1999), dentre outros.

Propomos ao leitor, porém, uma abordagem diferente, aproveitando o ensejo da identificação de diferentes contextos históricos e o impacto destes acontecimentos na construção de características comuns aos membros de grupos que dividam a mesma classe de idades.

2 Diferenças Geracionais: a importância do contexto histórico na transição para a vida adulta

Este modelo, proposto por Sheehy (1997) e utilizado por outros autores (PAPPAMIKAIL, 2004), propõe-se a analisar os processos de transição de saída da adolescência e entrada na vida adulta em diferentes grupos etários a luz da influência de acontecimentos históricos, políticos e sócio-econômicos comuns aos membros de cada grupo.

Este modelo leva em conta, portanto, que alguns comportamentos assumidos na maturidade possam ter sua gênese ou serem fortemente influenciados por experiência coletivas e individuais comuns a um grupo de indivíduos.

Ao propor esse enfoque micro e macrossocial, apesar de contrariar os princípios propostos pela teoria do construcionismo social, o modelo vai de encontro com outras teorias sociais do envelhecimento de terceira geração (SEIFFERT, 2001), principalmente a teoria do curso de vida.

A nosso ver, o modelo pode não justificar todas as origens de conflitos intergeracionais, mas permite identificar contextos sociais que possam ter permeado certos tipos de comportamento mais característicos de determinados grupos etários.

Segundo Sheehy (1997), cinco gerações diferentes ocupariam a maturidade contemporânea, com datas de nascimento que vão de 1914 a 1980. Segundo a autora, seriam assim divididas:

a) Geração da Segunda Guerra Mundial - 1914 a 1929;

b) Geração Silenciosa - 1930 a 1945;

c) Geração do Vietnã - 1946 a1955;

d) Geração do Eu - 1956 a 1965;

e) Geração Ameaçada - 1966 a 1980.

Concordamos que, tendo em vista o contexto social e histórico da sociedade brasileira, talvez algumas das denominações criadas pela autora 
(1997) para cada geração não sejam adequadas a nossa realidade. Esta constatação, porém, não minimiza a importância e adequabilidade das divisões estabelecidas para cada uma das cinco coortes.

Deste modo, convidamos o leitor a substituir a denominação Geração do Vietnã por Geração do Rompimento, termo que, acreditamos, possa ser adequado ao panorama histórico vivenciado pelos jovens que nasceram entre 1946 até 1955 e adentravam sua vida adulta nos meados da década de sessenta e setenta.

As demais denominações, por apresentarem características mais facilmente assimiláveis à realidade brasileira, serão mantidas conforme a proposta original de Sheehy (1997).

Nos parágrafos seguintes, convidamos o leitor a reviver alguns dos principais acontecimentos e contextos históricos (tanto mundiais quanto nacionais) vivenciados por estes atores sociais na transição de suas vidas de uma família de orientação para uma família de linhagem, o que Sheehy (1997) prefere chamar de ruptura das raízes.

Ao final de cada descrição tentaremos destacar alguns dos comportamentos culturais mais evidentes em cada segmento etário em função dos acontecimentos que vivenciaram nesta transição de suas vidas, sugerindo possíveis mecanismos envolvidos na aquisição de comportamentos que tenham influenciado as relações entre as gerações contemporâneas.

\subsection{Geração da Segunda Guerra Mundial (nascidos entre 1914-1929)}

Os membros deste grupo tinham aproximadamente 20 - 24 anos quando eclodiu a Segunda Guerra Mundial (GM). Segundo Sheehy (1997), além do impacto da GM, os efeitos da grande "Depressão" (crise econômica desencadeada à partir de 1929, com a quebra da Bolsa de Valores de Nova Iorque) devastaram famílias, empresas e economias nacionais. A autora complementa que, em função das dificuldades financeiras, muitos jovens desta geração atrasaram sua entrada na vida adulta.

Segundo Sheehy (1997) a maioria dos homens só se casou depois dos vinte e cinco anos. As mulheres, enquanto esperavam seus maridos e noivos que estavam na guerra, iam trabalhar para manterem as fábricas e o sustento da família, ou cuidavam dos irmãos e avós. Segundo a autora cerca de $70 \%$ das mulheres desta geração completaram seus estudos secundários somente com 35 - 39 anos, e menos de $6,4 \%$ terminaram o curso superior. 
No Brasil, o período coincidia com o final do Império e início da Primeira República. Surgiam as classes médias, apoiadas pelo surgimento do proletariado urbano; ao mesmo tempo, grandes movimentos migratórios procedentes principalmente da Europa inundavam o país.

Quando estes jovens (nascidos ou não no Brasil) estavam entrando na idade adulta, a história brasileira passava por momentos conturbados: conduzido ao poder pela Junta Militar que depôs Washington Luís, Getúlio Vargas tem seu governo marcado pelo aumento gradual da intervenção do Estado na economia e na organização da sociedade, combinados com o crescente autoritarismo e centralização do poder.

Os movimentos sociais se intensificavam e culminaram, em 1938, com o Golpe de Estado. O Brasil, apesar de manter-se neutro nos três primeiros anos da guerra, rompe com o Eixo e, em 1942, declara guerra contra a Alemanha e a Itália.

A nosso ver, os adolescentes desta geração, em função da repressão e do autoritarismo do Estado, e pela necessidade do suporte financeiro dos pais, acatavam com mais resignação as determinações das linhagens anteriores, especialmente os jovens oriundos de outras culturas e que agora assumiam o Brasil como sua nova pátria.

Não dispunham de meios de comunicação de massa, e por isso a transmissão de valores era predominantemente uma atribuição familial, o que gerava valor aos indivíduos com mais idade e experiência de vida.

Apesar da provável atitude pessimista dos pais, abalados pelas dificuldades financeiras e pela guerra, Sheehy (1997) defende que os jovens desta geração acreditavam que seu futuro poderia ser mais luminoso. Talvez por terem retardado sua saída de casa, os laços familiares e de coletivismo pareciam mais fortes, e a rede de suporte familiar parecia mais íntegra. Os próprios filhos e netos eram, geralmente, os cuidadores dos pais e avós envelhecidos.

\subsection{Geração Silenciosa (nascidos entre 1930-1945)}

Nascidos antes da televisão, esta geração conviveu com a paranóia do comunismo versus capitalismo. Enquanto cresciam os índices de escolaridade em ambos os sexos, principalmente nos países mais desenvolvidos, os jovens desta geração partiram mais cedo de casa, 
"rompendo suas raízes" na sua grande maioria antes dos vinte anos (SHEEHY, 1997).

No Brasil, esta geração conviveu com a instituição da Segunda República, e vivenciou na pele os primórdios do que viriam a serem os horrores do Golpe Militar de 1964.

Próximos da transição para a vida adulta, os adolescentes desta geração conviveram e observaram o contraste da estabilidade e confiança oferecidas durante o governo de Juscelino Kubitschek, com o crescimento galopante da inflação nos anos seguintes e a crise de confiança com a qual o país culminava no início de 1964, com um governo sem apoio da quase totalidade das classes dominantes.

Frente às dificuldades financeiras, ocorre maciça migração campocidade, e a população urbana brasileira supera a rural, devido ao crescimento do operariado.

Apesar disso, segundo Sheehy (1997), os membros desta geração exibiram as menores taxas no século XX para quase todas as patologias sociais da juventude: crimes, suicídio, gravidez na adolescência, etc. Em sua maioria, segundo a autora, respeitavam a autoridade e acreditavam nas instituições estatais.

Afirma ainda que esta foi a geração que se casou e formou família mais cedo, provavelmente para fugir do rigoroso e autoritário controle dos progenitores da geração anterior, rígidos por natureza devido ao contexto histórico que vivenciaram (guerras, recessão econômica, golpes militares).

A grande maioria dos homens norte-americanos desta geração já estavam casados com 24 anos, assim como $70 \%$ das mulheres - isso justifica, talvez, porque esta coorte detêm o recorde de maior fertilidade do século XX (SHEEHY, 1997).

Acreditamos que, no Brasil, esta foi a geração que deu início à fragmentação do núcleo familiar. Os adolescentes e adultos jovens, em busca de melhores condições de vida (e talvez buscando fugir do controle hierárquico das famílias de orientação), abandonam o meio rural, deixando para trás os familiares envelhecidos, muitas vezes sem o suporte familiar que as gerações anteriores dispunham.

Os jovens do meio urbano, expostos aos paradigmas que a modernidade e a educação formal agregavam ao seu modo de perceber a vida e as relações com os outros, influenciavam-se pelo clima de otimismo e 
revolução que as notícias vindas dos continentes europeu e americano traziam (O BRASIL na II Guerra Mundial, 2002).

As relações intergeracionais ainda são mantidas respeitando-se os princípios de hierarquia, mas frente à necessidade de transformar o seu próprio meio, os jovens nascidos nesta coorte, quando transitaram para a vida adulta, encontraram um panorama sócio-político diferenciado: precisavam reconstruir os modos através dos quais as transferências intergeracionais de recursos eram adotadas até então.

Segundo Turra e Queiroz (2005, p. 192): "Na maior parte das sociedades as crianças consomem os recursos gerados pelos adultos, transferidos pela família ou pelo setor público. Idosos, por sua vez, dispõe de ativos acumulados durante a fase ativa $[\ldots] .$.

Como estes adolescentes precisavam de recursos para iniciar suas novas vidas fora da família de orientação e, geralmente, distantes delas, as gerações anteriores precisaram transferir parte destes recursos para o investimento em seus membros mais novos.

Acontece que estes repagamentos, como preferem os mesmos autores, não foram negociados como esperavam as gerações anteriores, pois as novas necessidades vislumbradas pelos jovens eram diferentes das necessidades de quando seus progenitores tinham a mesma idade.

Apesar disto, porém, estes conflitos familiares ainda aconteciam de forma velada, de modo a que poucos eram os jovens que já insistiam em criar problemas de relacionamento com as gerações anteriores.

\subsection{Geração do Rompimento (nascidos entre 1946-1955)}

Na concepção de Sheehy (1997), os integrantes desta geração cresceram acreditando que podiam fazer praticamente qualquer coisa. Seus pais, em grande parte da Geração da Segunda Guerra Mundial, determinados a protegê-los das dificuldades que eles próprios haviam suportado, descortinaram para os filhos um mundo de oportunidades aparentemente ilimitadas, criando, na concepção da autora, uma geração de crianças mimadas.

Foi nesta geração que surgiu a televisão, e que o mundo descortinou as maravilhas de ser jovem. A adolescência havia se transformado num culto a ser prolongado, apreciado, e a receber as atenções do comércio como nunca antes. 
Surgem os Beatles, e, segundo Sheehy (1997) cria-se o mito de que os adultos não compreendem os jovens. Eles tinham entre 20 e 24 anos em 1970, ano em que o movimento de liberação da mulher veio a público e, consigo a libertinagem sexual e o uso da pílula anticoncepcional.

Os homens e mulheres desta geração fugiram da tradição de casamento antes dos 25 anos, causando uma espantosa queda nas taxas de natalidade.

Em terras brasileiras os membros desta geração chegam à maturidade imersos num contexto de autoritarismo, supressão dos direitos constitucionais, perseguição policial e militar, prisão e tortura, às voltas com os mandos e desmandos dos Atos Institucionais, mecanismos adotados pelos militares para legalizar as ações políticas não previstas e mesmo contrárias à Constituição.

A sociedade passa a viver sob um clima de terrorismo, principalmente após o fechamento do Congresso Nacional. Crescem os movimentos operários e os movimentos estudantis e populares. Segundo Silveira (2002) os novos ideais individualistas e o impacto das revoluções sociais dos anos 60 tornam mais frouxos os laços parentais, diminuindo a lealdade e o sentimento de reciprocidade para com os mais velhos na família. Sob o estímulo da mídia, cresce a barreira entre as condutas e comportamento desta para com as gerações que a precederam, tanto no Brasil quanto em outros países.

Os adultos passam a tomar como subversivas a maioria das ações dos jovens. Segundo Sheehy (1997, p. 115) um misto de utopia com massificação da personalidade coletiva define a juventude desta geração, "[ . .. ] voltada ao individualismo, contrária ao sistema, cabeluda, drogada, viciada em sexo."

Com o crescimento dos conflitos entre os indivíduos de diferentes grupos etários, em especial dos conservadores e tradicionais adultos velhos e idosos com esta subversiva juventude, os analistas sociais começam a esboçar os primeiros ensaios sobre o que viriam a ser os grandes conflitos intergeracionais dos anos 60-70 (SHEEHY, 1997).

Segundo Goldani (1999, p. 226), vários fatores, direta ou indiretamente, "[... ] reivindicam a existência de um conflito emergente entre as gerações, marcado pela disputa por recursos entre os grupos etários, particularmente entre crianças e idosos."

Este conflito, porém, parece desenvolver-se muito mais no campo sócio-político, uma vez que segundo a mesma autora, ele é raramente apontado em nível de contrato informal intra-familiar. Mas fato é que, 
indubitavelmente, já existem menos jovens disponíveis para assumir o cuidado dos entes mais envelhecidos e dependentes, e que na concepção das gerações anteriores, este papel social não está sendo cumprido por quem de direito.

\subsection{Geração do Eu (nascidos entre 1956-1965)}

Wolfe $^{1}$ (apud SHEEHY, 1997) foi quem cunhou o termo Década do Eu, para intitular os jovens que tinham um sonho de aprimorar o próprio eu. Estes jovens atingiram a maioridade com maior percepção de seus direitos adquiridos, e um retorno ao despertar do renascimento da religião. Os jovens do início da década de 80 tinham a prosperidade como líquida e certa.

Estes jovens completavam de 20 a 24 anos em torno de 1985, no auge dos excessos da década de 80, durante o qual, segundo Sheehy (1997) o governo americano tomou emprestado aos seus filhos e netos para financiar uma das mais complacentes orgias de gastos do século: a Guerra Fria e o poderio bélico.

Segundo Turra e Queiroz (2005,p. 193), as transferências familiares de recursos passam a constituir a principal fonte para a manutenção das crianças, enquanto "[... ] o setor público é o principal garantidor do consumo dos idosos."

O estudo e as facilidades de acesso à universidade fizeram com que essa geração criasse uma maior consciência de suas potencialidades. Houve um nítido aumento no número de mulheres no mercado de trabalho e, com isso, uma queda ainda mais brusca nas taxas de natalidade.

No Brasil chegava ao fim o Regime Militar, e instalava-se o período de Redemocratização. Cresciam as reivindicações populares, e com a restituição do pluripartidarismo, ganha forma o movimento de organização das "Diretas Já".

A economia volta a crescer, através principalmente dos setores da construção civil e de bens de consumo duráveis. Mas na década de 80 o Brasil mergulha em nova recessão, e sua principal conseqüência é o desemprego.

Findo o Regime Militar, os primeiros anos desta década são destinados à limpeza do entulho burocrático e autoritário criado pelos governos militares. É promulgada a Constituição de 1988, seguida pela eleição presidencial de 1989.

${ }^{1}$ WOLFE, Linda. Playing Around New York: Willian M., 1975. 
$\mathrm{O}$ adolescente desta geração, envolto na nova cultura pop-rock, explorado e influenciado pela massificação dos programas de TV, desenvolve uma necessidade de auto-afirmação, e novamente abandona o seio familiar precocemente, na busca por emprego.

Convive com os envelhecidos remanescentes da Geração da Segunda Guerra Mundial e Geração Silenciosa, na sua maioria extremamente conservadores, e por suas opções geralmente não tradicionais, agrava ainda mais as barreiras e diferenças entre jovens e velhos.

A redução progressiva nas taxas de natalidade das últimas gerações faz com que estes adolescentes vejam os seus idosos contemporâneos envelhecendo sozinhos, abandonados social e culturalmente.

Como os membros desta geração já tiveram melhores condições de estudo que as gerações anteriores, surgem os primeiros esboços de iniciativas em prol do acompanhamento e aproximação das gerações mais novas com as mais velhas. Parte dos "conflitos intergeracionais" passa a ser estudados e entendidos como um problema de relacionamento familiar e social, e não como uma patologia.

\subsection{Geração Ameaçada (nascidos entre 1966-1980)}

Com a facilidade de interação e acesso a informação disponibilizada pelos meios de comunicação (internet, televisão, revistas, etc.), os jovens que adentram a vida adulta nas décadas de 80 e 90 já parecem perceber que o mundo está menor.

Com a formação de mercados comuns, línguas, moedas e culturas diversas unem-se em prol do crescimento e emancipação sócio-econômica. Frente à facilidade de acesso aos estudos, milhares de jovens conseguem entrar e concluir o ensino superior, retardando a formação de suas famílias de procriação.

As taxas de fecundidade continuavam a despencar (agora de modo mais evidente também em países em desenvolvimento) e mais pessoas atingiam a vida adulta e idades avançadas: desenvolve-se, rapidamente, o processo posteriormente denominado de transição demográfica (KALACHE; VERAS; RAMOS, 1987).

Segundo Sheehy (1997) os acontecimentos históricos mais significativos desta época não envolvem mais tragédias em proporções avassaladoras como em outros tempos, mas sim através de um corredor de 
ameaças epidemiológicas da maturidade: aumentam os índices de suicídio adolescente, multiplicam-se os casos de gravidez precoce, abate-se o flagelo da AIDS.

São jovens que, devido ao contexto econômico e social, voltam a retardar sua saída de casa, atrasando sua entrada na vida adulta (SHEEHY, 1997). A maioria dos jovens não assume o compromisso do casamento antes dos 25 anos, o que reduz ainda mais os índices de fecundidade, e possibilita que ocorra um aumento substancial na proporção de indivíduos mais velhos quando comparados com crianças e jovens.

No Brasil, o crescimento desenfreado e imprevisível da violência acaba por tolher atos de liberdade em nome de segurança - foram crianças e jovens que cresceram trancafiados em seus próprios apartamentos, filhos de pais divorciados, sem os usuais referenciais de papéis sociais das gerações anteriores.

Os jovens desta geração vivenciam a primeira eleição direta para a presidência da República, após 21 anos de regime militar; ao mesmo tempo, vêm ampliadas suas possibilidades de participação social, com a redução nos limites de idade para o exercício do voto. Ás vésperas de alguns dos mais importantes acontecimentos políticos do país, participam das marchas dos caras pintadas que precederam ao impeachment do então presidente Fernando Collor de Mello.

Frente às conturbadas mudanças cambiais e a ascensão e queda de sucessivos governantes, os jovens dessa geração, portadores de mais bagagem intelectual, vislumbram na velhice um segmento de mercado em ascensão e a ser explorado. A velhice deixa de ser uma fase segregacionista para tornar-se um mercado lucrativo.

As distâncias entre esta geração e as gerações anteriores parecem diminuir, devido ao retorno da permanência prolongada destes jovens no seio familiar, estimulados pela luz dos avanços médicos que predizem uma vida longa para os nascidos nesta geração. Valores ainda enraizados convivem com os novos, modelizando um novo tipo de relacionamento entre as gerações, menos hierarquizado. Krischke (2004, p. 24) acredita que o enorme otimismo dos jovens brasileiros desta geração é atribuída “ [ . . . ] ao seu esforço pessoal e capacidade de inovação."

Apesar da manutenção das novas famílias nucleares, os jovens desta geração aproximam-se mais dos familiares e membros das gerações anteriores, 
ampliando as possibilidades de se lidar melhor com as regras e limites das gerações anteriores.

Silveira (2002) acredita que, a partir destas últimas décadas, a formação de grupos intergeracionais, não com o intuito de fomentar somente amizades por semelhança ou identificação, mas principalmente, de utilizar as diferenças em favor dos membros do grupo e da sociedade, é o que faz destes jovens uma coorte a parte.

\section{Considerações Finais}

Bell (1976) credita parte da gênese destas diferenças intergeracionais a uma nova "Revolução Industrial" que a população do último século foi exposta: a revolução que gerou a "Sociedade da Informação" e a globalização econômica.

Concordamos com o autor neste ponto, pois observamos que gradativamente parte dos valores de solidariedade e senso de coletivismo, comum às pequenas comunidades e sociedades, cede passo ao individualismo "narcisista" citado por Lyon (1994) e Lipovestky (1996). Os autores acreditam que esta visão individualista-narcista define mudanças no Eu, que fazem sucumbir a nitidez dos contornos sociais, dos papéis e das identidades, reduzindo as diferenças tradicionais de sexo, idade, autoridade e hierarquia.

Para Pappamikail (2004, p. 109), os jovens atualmente precisam aprender a lidar com a imprevisibilidade e instabilidade das relações contratuais entre as gerações, que "[ . . . ] exigem competências de flexibilidade e adaptabilidade num modo, até certo ponto, estranho à geração dos pais."

Na opinião de Markman (2000), analisando os resultados de trabalhos sobre as transformações ocorridas na juventude espanhola das últimas décadas, os valores de providência e tradição adotados pela juventude de outrora são hoje contrapostos ao paradigma orientador da modernidade, que toma em conta as noções de progresso material e do humanismo.

A autora observa, em especial se tratando da juventude espanhola dos anos noventa, que um processo de desideologização crescente e um aumento da individualização, que parecem nortear os novos valores sociais de convivência desta geração.

O final da adolescência, segundo Silveira (2002), é o momento de se investir na vida, no futuro, na carreira. Atitudes e comportamentos assumidos nesta fase da vida podem influenciar comportamentos futuros, e desencadear 
dificuldades em se lidar com assunção ou perda de papéis sociais a medida em que se ganham anos de vida.

Observamos, sim, que a modernidade incitou a produtividade capitalista como forma de tornar mais fácil a vida humana. Porém, no ímpeto de comprar a imagem de que o progresso constituía o fundamento da felicidade, nos parece que os valores de espírito passam a ser postergados em nome da racionalidade.

Analisando, porém, estudos sobre os valores dos jovens europeus dos anos oitenta e comparando-os com os realizados em 1994, Markman (2000) verificou que pais e filhos compartilham hoje mais opiniões e atitudes diante da vida.

O nível de conflitos intergeracionais parece diminuir, em nossa análise, talvez, pela permanência prolongada e crescente dos jovens destas últimas gerações no seio de suas famílias, em conseqüência das dificuldades profissionais e econômicas, e talvez por, devido a maior carga de educação formal, serem mais susceptíveis a adaptações.

Corroborando esta opinião destacamos alguns trabalhos europeus que, analisando o "índice de ideologização" de diferentes gerações, parecem comprovar esta aproximação. Esse índice é medido através da análise das respostas de como os entrevistados se situam politicamente em relação às posições de esquerda ou direita (MARKMAN, 2000; ORIZO, 1994).

Tendo o panorama político de países como a Holanda e Espanha permanecidos constantes nas últimas dezenas de anos, os autores observam que enquanto em 1981 a maioria dos pais se situava na posição da direita (enquanto os filhos se declaravam de esquerda), dados recentes mostram que os filhos modificaram sua tendência, aproximando-se das opiniões paternas.

Segundo Pappamikail (2004, p. 91-92):

[... ] o prolongamento da juventude traduziu-se na emergência de (re)definições e (re)configurações das dinâmicas de convivência familiar, ao mesmo tempo que os pais [ . . . ] se tornam, cada vez mais, no principal suporte financeiro e instrumental de apoio material nas trajetórias juvenis, incluindo a transição para a vida adulta. Pais e filhos vêem-se, assim 'obrigados' a negociar novos espaços de autonomia, 
bem como novas articulações entre os estados de dependência financeira $[\ldots]$.

Apesar da aparente aproximação das últimas gerações com seus predecessores, o mito atual de que os filhos adultos cada vez mais deixam de cuidar de seus pais idosos tem levado a projeções catastróficas de um idoso abandonado e isolado.

Não obstante, o próprio Estatuto do Idoso, promulgado pela constituinte brasileira através lei $\mathrm{n}^{\circ}{ }^{\mathrm{o}} 10.741$, de $1^{\mathrm{o}}$ de outubro de 2003, compreende que a "[ ... ] viabilização de formas alternativas de participação, ocupação e convívio do idoso com as demais gerações" deva ser percebido como uma prioridade de ação (BRASIL, 2003).

Experiências cativantes da formação de grupos intergeracionais, como as de França e Soares (1997, p. 151) sugerem que o uso das relações intergeracionais possa ser ferramenta útil para quebrar preconceitos. Afirmam que: “[...] as trocas geracionais não devem se limitar à família e aos programas e políticas governamentais, mas serem expandidas às instituições privadas e a outras representações da sociedade."

A presente análise, obviamente, não tem a pretensão de esgotar o assunto, mas apenas de convidar o leitor a perceber o impacto que o curso de vida de diferentes gerações pode agregar a problemática do envelhecimento populacional não programado em sociedades em desenvolvimento.

Talvez o desenvolvimento de uma classificação nacional para o estudo das gerações brasileiras seja muito mais produtivo e interessante que a aplicação histórica de um panorama baseado em padrões norte-americanos prévios.

Porém, por tratar-se de setor do conhecimento ainda pouco explorado, acreditamos que as reflexões aqui apresentadas possam, ao menos, estimular mais pesquisadores e estudiosos do tema a estenderem as informações aqui descritas.

Por fim, acreditamos que é possível ao leitor mais atento observar que mesmo essa ingênua análise já destaca importantes diferenças de comportamento entre gerações que dividem a atual maturidade contemporânea. É possível, porém, que muitos outros fatores influenciem o comportamento dessas gerações - ou, melhor ainda, de outras gerações criadas segundo contextos genuinamente nacionais. 


\title{
INTERGENERATIONAL DIFFERENCES IN THE BRAZILIAN CONTEXT: reflections and perspectives
}

\begin{abstract}
The exposure of a group of people with similar ages to the same economical, social, cultural and historical problems is what defines the concept of generation. Through the analisys of the historical events that the last decade's generations passed by, it has been created a classification following northamerican patterns, to which we added informations about the brazillian context, in order to stimulate the debate about the perceptions of these differences in the genesis of the present conflict between the elderly and the youth.

Keywords: Intergenerational Relations. Cohort Effect. Intergenerationality.
\end{abstract}

\section{REFERÊNCIAS}

BELL, Daniel. El advenimiento de la sociedad postmoderna: um intento de prognosis social. Madrid: Alianza, 1976.

BRASIL. Lei n ${ }^{\circ} 10.741$, de $1^{\circ}$ de outubro de 2003. Dispõe sobre o Estatuto do Idosos e dá outras providências. Diário Oficial [da] União, Brasília, DF, 03 outubro de 2003. Disponível em: <http://www.planalto.gov.br/ CCIVIL/leis/2003/L10.741.htm>. Acesso em: 01 set 2006

CASTILHO, Tai. Família e Relacionamento de Gerações. In: CONGRESSO INTERNACIONAL CO-EDUCAÇÃO DE GERAÇÕES SESC, 1., 2003, São Paulo. Anais...São Paulo: SESC, [2003?].

COELHO, Maria da Graça. O Idoso Isolado e as Gerações. 1988.109 p. Monografia (Especialização em Gerontologia Social) - Universidade Federal de Santa Catarina, Florianópolis, 1988.

FRANÇA, Lucia Helena; SOARES, Neusa Eiras. A Importância das Relações Intergeracionais na Quebra de Preconceitos sobre a Velhice. In: VERAS, Renato P. (Org.). Terceira Idade: desafios para o terceiro milênio. Rio de Janeiro: Relume-Dumará, 1997. P. 143-169. 
GOLDANI, Ana Maria. Relações Intergeracionais e Reconstrução do Estado de Bem Estar: por que se deve repensar essa relação para o Brasil. [S.1.: s.n.], 2004. Disponível em: <http://www.abep.nepo.unicamp.br/docs/ PopPobreza/GoldaniAnaMariaCapitulo7.pdf>. Acesso em: 10 out. 2004.

KALACHE, Alexandre; VERAS, Renato P.; RAMOS, Luiz R. O Envelhecimento da População Mundial: um desafio novo. Revista de Saúde Pública, São Paulo, v. 21, n. 3, p. 200-210, 1987.

LAUFER, Robert S.; BENGSTON, Vern L. Generations, Aging and Social Stratification and the Development of Generational Units. Journal of Social Issues, Washington, v. 30, p. 181-205, 1974.

LIPOVESTKY, Gilles. La era del vacio: ensayos sobre el individualismo. Barcelona: Anagrana, 1996.

LYON, David. Postmodernidad. Madrid: Alianza Editorial, 1994.

KRISCHKE, Paulo J. Perfil da Juventude Brasileira: questões sobre cultura política e participação democrática. Revista Internacional Interdisciplinar INTHERtesis, Florianópolis, v. 2, n. 2, 2004. Disponível em: <http:// www.interthesis.cfh.ufsc.br/interthesis2/artigo3.pdf $>$. Acesso em: 01 set. 2006.

MARKMAN, Rejane. Mundialização Cultural e Juventude: mudanças nos valores culturais dos jovens espanhóis. Madrid, 2000. Disponível em: < http://www.eca.usp.br/nucleos/nce/pdf/137.pdf>. Acesso em: 10 out. 2004.

MORAGAS, Ricardo M. Gerontologia Social. São Paulo: Paulinas, 1997.

MORIN, Edgar. Cultura de Massa no Século XX: o espírito do tempo. Rio de Janeiro: Forense Universitária, 1967.

O BRASIL na II Guerra Mundial. Disponível em: <http:// www.historianet.com.br/conteudo/default.aspx?codigo $=406>$. Acesso em: 01 set. 2006. 
ORIZO, Francisco Andrés. Dinamica intergeracional en los sistemas de valores de los españoles. Madrid: Alianza Editorial, 1994.

PAPPAMIKAIL, Lia. Relações Intergeracionais, Apoio Familiar e Transições Juvenis para a Vida Adulta em Portugal. Sociologia, Problemas e Práticas, Lisboa, v. 46, p. 91-116, 2004.

RIFIOTIS, Theophilos. Grupos Etários e Conflito de Gerações: bases antropológicas para um diálogo interdisciplinar. Revista Política \& Trabalho, São Paulo, v. 1, p. 105-123, set. 1995.

SEIFFERT, Raquel Q. Gerontologia: introdução sócio-política. Florianópolis: Copyflo, 2001.

SILVEIRA, Theresinha Mello da. Convívio de Gerações: ampliando possibilidades. Textos sobre o Envelhecimento, Rio de Janeiro, v. 4, n. 8, p. 152-159, jan. 2002. Disponível em: <http://www.unati.uerj.br/tse/ scielo.php?script $=$ sci_arttext\&pid $=$ S 1517-5928200200020000 $2 \& \operatorname{lng}=$ pt\&nrm=iso $>$. Acesso em: 01 set. 2006

SHEEHY, Gail. Novas Passagens. Rio de Janeiro: Rocco, 1997.

TURRA, Cássio Maldonado; QUEIROZ, Bernardo Lanza. Transferências Intergeracionais: uma análise internacional. Revista Brasileira de Estudos Populacionais, São Paulo, v. 22, n. 1, p. 191-194, jan./jun. 2005. 